\title{
Pengaruh Lama Penyeduhan Terhadap Kualitas Dan Jumlah Padatan Minuman Kopi Seduh Dingin Kopi Arabica Flores Bajawa
}

\author{
Rezky Haryono ${ }^{1, a)}$, Ridawati2,b) dan Mariani ${ }^{3, \mathrm{c})}$ \\ 1,2,3 Program Studi Pendidikan Tata Boga, Universitas Negeri Jakarta, Jalan Rawamangun Muka, \\ DKI Jakarta, 13220 \\ Email: ${ }^{\text {a) }}$ rezkyharyono.31@ gmail.com, ${ }^{\text {b) }}$ ridawati.sesil@ gmail.com, ${ }^{\text {c) }}$ mariani.ikk@gmail.com
}

\begin{abstract}
Coffee is one of the most traded commodities in the world, quoted from the oec.world website (2018) with a total trade of 30.9 billion USD. Consuming coffee has many positive benefits, quoted from the journal review on health benefits and risks of coffee consumption, consuming cafeine from coffee can increase physical performance, burn fat, reduce the risk of stroke, liver and prostate cancer by $20 \%$. Quoted from the journal acidity and antioxidant activity of cold brew (2018), cold brewed coffee drinks have lower acidity when compared to hot brewed coffee drinks with the same amount of coffee, making it a more acceptable choice for those who suffer from GERD (gastroesophageal reflux disease or stomach acid) and ulcers (www.healthline.com, 2018). This research aims to examine different brewing times $(6,12,18$ and 24 hours) by examining the organoleptic quality of cold brewed coffee from various quality aspects such as aroma, flavor, balance, aftertaste, acidity, sweetness, body and total dissolved solids to expert panelists using experimental methods. The results showed that there was a sensory effect on cold brewed coffee with different brewing times. Based on research, cold brewed coffee with 24 hours of brewing time has the highest value in every aspect compared to brewing times of 6,12 and 18 hours. Where the flavor aspect has a value of 7.02 (very good), balanced has a value of 6.93 (good), aftertaste has a value of 7.01 (very good), acidity has a value of 6.85 (good), sweetness has a value of 6, 87 (good) and body has a value of 6.97 (good).
\end{abstract}

Keywords : cold brewed coffee, coffee quality, total dissolved solids

\begin{abstract}
Abstrak
Kopi merupakan salah satu komoditas yang paling sering diperdagangkan di dunia, dikutip dari website oec.world (2018) dengan total perdagangan 30.9 miliar USD. Mengkonsumsi kopi memiliki banyak manfaat positif, dikutip dari jurnal review on health benefit and risk of coffee consumption mengkonsumsi kafein dalam kopi dapat meningkatkan kinerja fisik, membakar lemak, mengurangi resiko stroke, kanker hati dan prostat sebanyak 20\%. Dikutip dari jurnal acidity and antioxidant activity of cold brew (2018) minuman kopi seduh dingin memiliki kadar keasaman yang lebih rendah jika dibandingkan dengan minuman kopi yang diseduh menggunakan air panas, sehingga membuatnya menjadi pilihan yang lebih dapat diterima bagi mereka yang menderita GERD (gastroesophageal reflux disease atau asam lambung) dan maag (www.healthline.com, 2018). Penelitian ini bertujuan untuk meneliti lama penyeduhan yang berbeda-beda $(6,12,18$ dan 24 jam) dengan menguji kualitas minuman kopi seduh dingin dari berbagai aspek kualitas seperti aroma, flavor, balance, aftertaste, acidity, sweetness, body dan jumlah padatan terlarut kepada panelis ahli dengan menggunakan metode eksperimen. Hasil penelitian menunjukan terdapat pengaruh sensoris pada kopi seduh dingin dengan lama penyeduhan yang berbeda-beda. Berdasarkan penelitian, kopi seduh dingin dengan lama
\end{abstract}


penyeduhan 24 jam memiliki nilai tertinggi di setiap aspek dibandingkan dengan waktu penyeduhan 6 , 12 dan 18 jam. Dimana pada aspek flavor memiliki nilai 7,02 (very good), balanced memiliki nilai 6,93 (good), aftertaste memiliki nilai 7,01 (very good), avidity memiliki nilai 6,85 (good), sweetness memiliki nilai 6,87 (good) dan body memiliki nilai 6,97 (good).

Kata kunci : kopi seduh dingin, kualitas kopi, jumlah padatan terlarut

\section{PENDAHULUAN}

Kopi merupakan salah satu komoditas yang paling sering diperdagangkan di dunia, dikutip dari website oec.world (2018) dengan total perdagangan 30.9 miliar USD. Menurut International Coffee Organization (ICO) kopi pada tahun 2019/2020 dikonsumsi sebanyak 9.8 milyar kilogram, naik 2.2\% dari tahun 2016/2017. Konsumsi kopi di Indonesia pada tahun 2019/2020 sendiri meningkat mencapai 286 juta kilogram dan diprediksi setiap tahun terus meningkat. Mengkonsumsi kopi memiliki banyak manfaat positif seperti kinerja fisik, membakar lemak, mengurangi resiko stroke, kanker hati dan prostat sebanyak 20\%. Umumnya minuman kopi diseduh menggunakan air bersuhu tinggi; pada suhu air $90,5-96^{\circ} \mathrm{C}\left(195-205^{\circ} \mathrm{F}\right)$. Namun, saat ini muncul metode penyeduhan minuman kopi yang dilakukan pada suhu kamar $\left(20^{\circ} \mathrm{C}\right.$ hingga $\left.25^{\circ} \mathrm{C}\right)$, yaitu penyeduhan minuman kopi dengan metode seduh dingin. Metode seduh dingin dilakukan dengan waktu penyeduhan yang lebih panjang (3-24 jam) jika dibandingkan dengan metode seduh panas dengan tujuan mendapatkan hasil ekstraksi minuman kopi secara maksimal. Waktu penyeduhan yang lebih panjang dilakukan dengan tujuan meningkatkan kontak antara bubuk kopi dan air (Callow, 2017). Dikutip dari jurnal acidity and antioxidant activity of cold brew (2018) minuman kopi seduh dingin memiliki kadar keasaman yang lebih rendah jika dibandingkan dengan minuman kopi yang diseduh menggunakan air panas, sehingga membuatnya menjadi pilihan yang lebih dapat diterima bagi mereka yang menderita GERD (gastroesophageal reflux disease atau asam lambung) dan maag (www.healthline.com, 2018).

Air menyusun lebih dari 90\% volume minuman kopi (Hoffmann, 2014). Air memiliki peran penting dalam penyeduhan kopi yaitu sebagai media seduh/perantara yang digunakan untuk mengekstrak zat dan partikel yang dmiliki kopi. Pentingnya air dalam penyeduhan kopi seduh dingin disebabkan oleh sifat air sebagai pelarut partikel, dengan kata lain bubuk kopi yang diseduh akan terlarut dan terabsorbsi ke dalam air, membuat air memiliki cita rasa yang dimiliki kopi. Air yang dikatakan berkualitas untuk digunakan dalam penyeduhan minuman kopi adalah air dengan kadar $\mathrm{pH}$ netral ( $\mathrm{pH}$ 7) serta tidak memiliki rasa dan aroma yang mengganggu agar kopi yang dihasilkan menjadi lebih terasa (Sumarni dan Respati, 2015).

Uji organoleptik merupakan salah satu cara yang digunakan untuk mengetahui daya terima suatu produk serta untuk menilai mutu suatu bahan pangan dan penelitian organoleptik merupakan penilaian dengan cara memberi rangsangan terhadap organ tubuh (Soekarto, 1985). Pengujian sifat organoleptik menggunakan uji mutu hedonik yaitu uji hedonik yang lebih spesifik yang biasanya bertujuan untuk mengetahui respon terhadap sifat mutu organoleptik. Khususnya pada kualitas kopi seperti aroma, flavor, balance, aftertaste, acidity, sweetness, dan body. Untuk penilaian mutu atau analisa sifat-sifat sensorik suatu komoditi panel bertindak sebagai instrument atau alat. Panel adalah satu atau sekolompok orang yang bertugas untuk menilai sifat atau mutu benda berdasarkan kesan subyektif dari para panelis dengan prosedur sensorik tertentu yang harus dituruti. Menurut Alsuhendra dan Ridawati (2008) terdapat tujuh kelompok panel dalam melakukan penilaian organoleptik yang memiliki sifat dan keahlian tertentu tergantung pada tujuan penelitian. Yaitu panel perseorangan, panel terbatas, panel terlatih, panel agak terlatih, panel tidak terlatih, panel konsumen dan panel anak-anak.

Tujuan dari penelitian ini adalah untuk mengetahui dan menganalisis pengaruh lama penyeduhan terhadap kualitas organoleptik dan jumlah padatan terlarut minuman kopi seduh dingin dimana pada penelitian ini menggunakan kopi arabika dari flores bajawa.

\section{METODE PENELITIAN}

Dalam penelitian ini menggunakan metode eksperimen. Metode eksperimen yaitu metode penelitian yang mengadakan kegiatan uji coba untuk melihat hasil produk. Hasil itu akan 
menegaskan bagaimana hubungan antara variabel lama penyeduhan dengan variabel kualitas dan jumlah padatan terlarut minuman kopi seduh dingin kopi arabika flores bajawa.

Instrumen penelitian yang digunakan dalam penelitian ini adalah kuesioner, dimana setiap responden mendapatkan cupping form yang memiliki 7 indikator yaitu aroma, flavour, balance, aftertaste, acidity, sweetness, dan body dengan skala penilaian SCA (Specialty Coffee Association).

Populasi yang diteliti adalah ahli kopi yang terdiri dar barista dan roaster dengan jumlah sampel sebanyak 15 responden dengan tingkat ketelitian $\alpha$ sebesar 5\% dengan tingkat kepercayaan 95\% sehingga diperoleh $\mathrm{Z}=9,04$

\section{Uji Laboratorium}

Uji laboratorium dilakukan untuk mengukur kadar kepkatan padatan terlarut yang terdapat pada kopi seduh dingin dengan lama penyeduhan $6,12,18$ dan 24 jam. Alat yang digunakan pada uji ini adalah refractometer. Pada penelitian ini dilakukan pengukuran jumlah padatan terlarut dengan dua sampel berbeda pada waktu penyeduhan $6,12,18$ dan 24 jam dengan hasil, minuman kopi seduh dingin dengan lama penyeduhan 6 jam memiliki kadar kepekatan 1,18\% (sampel I) dan 1,18\% (sampel II), minuman kopi seduh dingin dengan lama penyeduhan 12 jam memiliki kadar kepekatan $1,26 \%$ (sampel I) dan 1,23\% (sampel II), minuman kopi seduh dingin dengan lama penyeduhan 18 jam memiliki kadar kepekatan 1,31\% (sampel I) dan 1,31\% (sampel II), minuman kopi seduh dingin dengan lama penyeduhan 6 jam memiliki kadar kepekatan 1,40\% (sampel I) dan 1,36\% (sampel II). Untuk lebih jelasnya bisa dilihat pada tabel berikut :

TABEL 1. Hasil Uji Lab Pengukuran Kadar Kepekatan

\begin{tabular}{ccc}
\hline \multirow{2}{*}{ Lama Penyeduhan } & \multicolumn{2}{c}{ Sampel } \\
\cline { 2 - 3 } & I & II \\
\hline 6 jam & $1,18 \%$ & $1,18 \%$ \\
12 jam & $1,26 \%$ & $1,23 \%$ \\
18 jam & $1,31 \%$ & $1,31 \%$ \\
24 jam & $1,40 \%$ & $1,36 \%$ \\
\hline
\end{tabular}

Dilihat di grafik coffee brewing control, dipaparkan bahwa kopi yang memenuhi golden cup standart adalah kopi yang memiliki tingkat kepekatan 1.15-1.35\%. Berdasarkan hal tersebut maka semua produk minuman kopi seduh dingin sudah memenuhi golden cup standart, kecuali produk minuman kopi dengan lama penyeduhan 24 jam.

\section{HASIL DAN PEMBAHASAN}

Data dari hasil penelitian ini diperoleh dari dua tahap. Tahap yang pertaman yaitu merupakan uji validasi intrumen dan produk yang dilakukan mterhadap 5 penguji yang teridir dari 2 dosen ahli dan 3 orang praktisi kopi, dimana uji ini dilakukan untuk menetapkan standar prdouk terbaik yang didapatkan untuk kemudian diteruskan dengan uji mutu sensoris. Uji mutu sensoris kemudian dilakukan terhadap 15 orang panelis terlatih yang berprofesi sebagai barista pada salah satu coffee shop yang bernama Kocil Specialty Coffee \& Roastery. Hasil penelitian ini adalah meliputi hasil uji validitas, uji mutu sensoris dan pengujian hipotesis yang menggunakan uji kruskal wallis.

Aroma

TABEL 2. Hasil Uji Penilaian Aspek Aroma

\begin{tabular}{ccccccccc}
\hline \multirow{2}{*}{ Skor } & \multicolumn{6}{c}{ Lama Penyeduhan Minuman Kopi Seduh Dingin } \\
\cline { 2 - 8 } & \multicolumn{2}{c}{ 6 Jam } & \multicolumn{2}{c}{ 12 Jam } & \multicolumn{1}{c}{ 18 Jam } & 24 Jam \\
\cline { 2 - 8 } & $\mathrm{N}$ & $\%$ & $\mathrm{n}$ & $\%$ & $\mathrm{n}$ & $\%$ & $\mathrm{n}$ & $\%$ \\
\hline 6.00 & 4 & $26.67 \%$ & 1 & $6.67 \%$ & 1 & $6.67 \%$ & & \\
6.25 & 2 & $13.33 \%$ & & & & & &
\end{tabular}




\begin{tabular}{ccccccccc}
6.50 & 6 & $40 \%$ & 5 & $33.33 \%$ & 4 & $26.67 \%$ & 1 & $6.67 \%$ \\
6.75 & 1 & $6.67 \%$ & 4 & $26.67 \%$ & 1 & $6.67 \%$ & 1 & $6.67 \%$ \\
7.00 & 2 & $13.33 \%$ & 5 & $33.33 \%$ & 9 & $60 \%$ & 13 & 86.67 \\
7.25 & & & & & & & & \\
7.50 & & & & & & & & \\
\hline Jumlah (N) & 15 & $100 \%$ & 15 & $100 \%$ & 15 & $100 \%$ & 15 & $100 \%$ \\
\hline Mean & 6.42 & & 6.7 & & 6.78 & 6.95 \\
\hline
\end{tabular}

Hasil penelitian pada aspek aroma kopi seduh dingin dengan lama waktu penyeduhan yang berbeda dieperoleh nilai rata-rata 6,42 untuk lama penyeduhan 6 jam, 6,7 untuk lama penyeduhan 12 jam, 6,78 untuk lama penyeduhan 18 jam dan 6,95 untuk lama penyeduhanb 24 jam. Pada uji kruskal wallis aspek aroma memperoleh nilai 37,04 $>9,4$ dengan taraf signifikansi $\alpha=0,05$ yang berarti terdapat pengaruh lama penyeduhan kopi seduh dingin terhadap aspek aroma.

Flavor

TABEL 3. Hasil Uji Penilaian Aspek Flavor

\begin{tabular}{|c|c|c|c|c|c|c|c|c|}
\hline \multirow{3}{*}{ Skor } & \multicolumn{8}{|c|}{ Lama Penyeduhan Minuman Kopi Seduh Dingin } \\
\hline & \multicolumn{2}{|c|}{ 6 Jam } & \multicolumn{2}{|c|}{ 12 Jam } & \multicolumn{2}{|c|}{ 18 Jam } & \multicolumn{2}{|c|}{ 24 Jam } \\
\hline & $\mathbf{N}$ & $\%$ & $\mathbf{n}$ & $\%$ & $\mathbf{n}$ & $\%$ & $\mathbf{n}$ & $\%$ \\
\hline 6.00 & 4 & $26.67 \%$ & & & & & & \\
\hline 6.25 & 2 & $13.33 \%$ & 1 & $6.67 \%$ & & & & \\
\hline 6.50 & 7 & $46.67 \%$ & 4 & $26.67 \%$ & 3 & $20 \%$ & 1 & $6.67 \%$ \\
\hline 6.75 & 1 & $6.67 \%$ & 6 & $40 \%$ & 2 & $13.33 \%$ & 1 & $6.67 \%$ \\
\hline 7.00 & 1 & $6.67 \%$ & 4 & $26.67 \%$ & 7 & $46.67 \%$ & 10 & $66.67 \%$ \\
\hline 7.25 & & & & & 2 & $13.33 \%$ & 2 & $13.33 \%$ \\
\hline 7.50 & & & & & 1 & $6.67 \%$ & 1 & $6.67 \%$ \\
\hline Jumlah (N) & 15 & $100 \%$ & 15 & $100 \%$ & 15 & $100 \%$ & 15 & $100 \%$ \\
\hline Mean & \multicolumn{2}{|c|}{6.38} & \multicolumn{2}{|c|}{6.72} & \multicolumn{2}{|c|}{6.94} & \multicolumn{2}{|c|}{7.01} \\
\hline
\end{tabular}

Hasil penelitian pada aspek flavor kopi seduh dingin dengan lama waktu penyeduhan yang berbeda dieperoleh nilai rata-rata 6,38 untuk lama penyeduhan 6 jam, 6,72 untuk lama penyeduhan 12 jam, 6,94 untuk lama penyeduhan 18 jam dan 7.01 untuk lama penyeduhanb 24 jam. Pada uji kruskal wallis diperoleh nilai 20,63>9,4 dengan taraf signifikansi $\alpha=0,05$ yang berarti terdapat pengaruh lama penyeduhan kopi seduh dingin terhadap aspek flavor.

\section{Balanced}

TABEL 4. Hasil Uji Penilaian Aspek Balanced

\begin{tabular}{|c|c|c|c|c|c|c|c|c|}
\hline \multirow{3}{*}{ Skor } & \multicolumn{8}{|c|}{ Lama Penyeduhan Minuman Kopi Seduh Dingin } \\
\hline & \multicolumn{2}{|c|}{ 6 Jam } & \multicolumn{2}{|c|}{12 Jam } & \multicolumn{2}{|c|}{ 18 Jam } & \multicolumn{2}{|c|}{ 24 Jam } \\
\hline & $\mathbf{N}$ & $\%$ & $\mathbf{n}$ & $\%$ & $\mathbf{n}$ & $\%$ & $\mathbf{N}$ & $\%$ \\
\hline 6.00 & 5 & $33.33 \%$ & & & & & & \\
\hline 6.25 & 1 & $6.67 \%$ & 1 & $6.67 \%$ & & & & \\
\hline 6.50 & 7 & $46.67 \%$ & 4 & $26.67 \%$ & 2 & $13.33 \%$ & 2 & $13.33 \%$ \\
\hline 6.75 & 1 & $6.67 \%$ & 5 & $33.33 \%$ & 2 & $13.33 \%$ & 1 & $6.67 \%$ \\
\hline 7.00 & 1 & $6.67 \%$ & 4 & $26.67 \%$ & 10 & $66.67 \%$ & 11 & $73.33 \%$ \\
\hline 7.25 & & & 1 & $6.67 \%$ & 1 & $6.67 \%$ & 1 & $6.67 \%$ \\
\hline \multicolumn{9}{|l|}{7.50} \\
\hline Jumlah (N) & 15 & $100 \%$ & 15 & $100 \%$ & 15 & $100 \%$ & 15 & $100 \%$ \\
\hline Mean & \multicolumn{2}{|c|}{6.36} & \multicolumn{2}{|c|}{6.75} & \multicolumn{2}{|c|}{6.91} & \multicolumn{2}{|c|}{6.93} \\
\hline
\end{tabular}

Hasil penelitian pada aspek balanced kopi seduh dingin dengan lama waktu penyeduhan yang berbeda dieperoleh nilai rata-rata 6,36 untuk lama penyeduhan 6 jam, 6,75 untuk lama penyeduhan 
12 jam, 6,91 untuk lama penyeduhan 18 jam dan 6,93 untuk lama penyeduhanb 24 jam. Pada uji kruskal wallis diperoleh nilai $21,24>9,4$ dengan taraf signifikansi $\alpha=0,05$ yang berarti terdapat pengaruh lama penyeduhan kopi seduh dingin terhadap aspek balanced.

\section{Aftertaste}

TABEL 5. Hasil Uji Penilaian Aspek Aftertaste

\begin{tabular}{|c|c|c|c|c|c|c|c|c|}
\hline \multirow{3}{*}{ Skor } & \multicolumn{8}{|c|}{ Lama Penyeduhan Minuman Kopi Seduh Dingin } \\
\hline & \multicolumn{2}{|c|}{$6 \mathrm{Jam}$} & \multicolumn{2}{|c|}{$12 \mathrm{Jam}$} & \multicolumn{2}{|c|}{$18 \mathrm{Jam}$} & \multicolumn{2}{|c|}{$24 \mathrm{Jam}$} \\
\hline & $\mathrm{N}$ & $\%$ & $\mathrm{n}$ & $\%$ & $\mathrm{n}$ & $\%$ & $\mathrm{n}$ & $\%$ \\
\hline 6.00 & 8 & $53.33 \%$ & 1 & $6.67 \%$ & & & & \\
\hline 6.25 & & & & & 1 & $6.67 \%$ & & \\
\hline 6.50 & 5 & $33.33 \%$ & 5 & $33.33 \%$ & 3 & $20 \%$ & & \\
\hline 6.75 & 1 & $6.67 \%$ & 3 & $20 \%$ & 2 & $13.33 \%$ & 2 & $13.33 \%$ \\
\hline 7.00 & 1 & $6.67 \%$ & 5 & $33.33 \%$ & 7 & $46.67 \%$ & 11 & $73.33 \%$ \\
\hline 7.25 & & & & & 1 & $6.67 \%$ & 1 & $6.67 \%$ \\
\hline 7.50 & & & 1 & $6.67 \%$ & 1 & $6.67 \%$ & 1 & $6.67 \%$ \\
\hline Jumlah (N) & 15 & $100 \%$ & 15 & $100 \%$ & 15 & $100 \%$ & 15 & $100 \%$ \\
\hline Mean & & & & & & 86 & & 11 \\
\hline
\end{tabular}

Hasil penelitian pada aspek aftertaste kopi seduh dingin dengan lama waktu penyeduhan yang berbeda dieperoleh nilai rata-rata 6,28 untuk lama penyeduhan 6 jam, 6,75 untuk lama penyeduhan 12 jam, 6,86 untuk lama penyeduhan 18 jam dan 7,01 untuk lama penyeduhanb 24 jam. Pada uji kruskal wallis diperoleh nilai 21,07>9,4 dengan taraf signifikansi $\alpha=0,05$ yang berarti terdapat pengaruh lama penyeduhan kopi seduh dingin terhadap aspek aftertaste.

\section{Acidity}

TABEL 6. Hasil Uji Penilaian Aspek Acidity

\begin{tabular}{|c|c|c|c|c|c|c|c|c|}
\hline \multirow{3}{*}{ Skor } & \multicolumn{8}{|c|}{ Lama Penyeduhan Minuman Kopi Seduh Dingin } \\
\hline & \multicolumn{2}{|c|}{$6 \mathrm{Jam}$} & \multicolumn{2}{|c|}{$12 \mathrm{Jam}$} & \multicolumn{2}{|c|}{$18 \mathrm{Jam}$} & \multicolumn{2}{|c|}{$24 \mathrm{Jam}$} \\
\hline & $\mathrm{N}$ & $\%$ & $\mathrm{n}$ & $\%$ & $\mathrm{n}$ & $\%$ & $\mathrm{n}$ & $\%$ \\
\hline 6.00 & 8 & $53.33 \%$ & 1 & $6.67 \%$ & 1 & $6.67 \%$ & & \\
\hline \multicolumn{9}{|l|}{6.25} \\
\hline 6.50 & 4 & $26.66 \%$ & 7 & $46.66 \%$ & 6 & $40 \%$ & 4 & $26.66 \%$ \\
\hline 6.75 & 2 & $13.33 \%$ & 2 & $13.33 \%$ & 1 & $6.67 \%$ & 1 & $6.67 \%$ \\
\hline 7.00 & 1 & $6.67 \%$ & 5 & $33.33 \%$ & 7 & $46.66 \%$ & 10 & $66.67 \%$ \\
\hline \multicolumn{9}{|l|}{7.25} \\
\hline 7.50 & & & & & & & & \\
\hline Jumlah (N) & 15 & $100 \%$ & 15 & $100 \%$ & 15 & $100 \%$ & 15 & $100 \%$ \\
\hline Mean & & & & & & 71 & & 35 \\
\hline
\end{tabular}

Hasil penelitian pada aspek acidity kopi seduh dingin dengan lama waktu penyeduhan yang berbeda dieperoleh nilai rata-rata 6,30 untuk lama penyeduhan 6 jam, 6,67 untuk lama penyeduhan 12 jam, 6,71 untuk lama penyeduhan 18 jam dan 6,85 untuk lama penyeduhanb 24 jam. Pada uji kruskal wallis diperoleh nilai $14,83>9,4$ dengan taraf signifikansi $\alpha=0,05$ yang berarti terdapat pengaruh lama penyeduhan kopi seduh dingin terhadap aspek acidity. 


\section{Sweetness}

TABEL 7. Hasil Uji Penilaian Aspek Sweetness

\begin{tabular}{|c|c|c|c|c|c|c|c|c|}
\hline \multirow{3}{*}{ Skor } & \multicolumn{8}{|c|}{ Lama Penyeduhan Minuman Kopi Seduh Dingin } \\
\hline & \multicolumn{2}{|c|}{$6 \mathrm{Jam}$} & \multicolumn{2}{|c|}{ 12 Jam } & \multicolumn{2}{|c|}{18 Jam } & \multicolumn{2}{|c|}{$24 \mathrm{Jam}$} \\
\hline & $\mathrm{N}$ & $\%$ & $\mathrm{n}$ & $\%$ & $\mathrm{n}$ & $\%$ & $\mathrm{n}$ & $\%$ \\
\hline 6.00 & 6 & $40 \%$ & 1 & $6.67 \%$ & & & & \\
\hline 6.25 & 3 & $20 \%$ & & & & & & \\
\hline 6.50 & 6 & $40 \%$ & 12 & $80 \%$ & 6 & $40 \%$ & 4 & $26.67 \%$ \\
\hline 6.75 & & & & & 1 & $6.67 \%$ & 1 & $6.67 \%$ \\
\hline 7.00 & & & 2 & $13.33 \%$ & 7 & $46.67 \%$ & 9 & $60 \%$ \\
\hline 7.25 & & & & & 1 & $6.67 \%$ & 1 & $6.67 \%$ \\
\hline \multicolumn{9}{|l|}{7.50} \\
\hline Jumlah (N) & 15 & $100 \%$ & 15 & $100 \%$ & 15 & $100 \%$ & 15 & $100 \%$ \\
\hline Mean & \multicolumn{2}{|c|}{6.25} & \multicolumn{2}{|c|}{6.53} & \multicolumn{2}{|c|}{6.80} & \multicolumn{2}{|c|}{6.86} \\
\hline
\end{tabular}

Hasil penelitian pada aspek sweetness kopi seduh dingin dengan lama waktu penyeduhan yang berbeda dieperoleh nilai rata-rata 6,25 untuk lama penyeduhan 6 jam, 6,53 untuk lama penyeduhan 12 jam, 6,80 untuk lama penyeduhan 18 jam dan 6,86 untuk lama penyeduhanb 24 jam. Pada uji kruskal wallis diperoleh nilai 26,42>9,4 dengan taraf signifikansi $\alpha=0,05$ yang berarti terdapat pengaruh lama penyeduhan kopi seduh dingin terhadap aspek sweetness.

\section{Body}

TABEL 8. Hasil Uji Penilaian Aspek Body

\begin{tabular}{|c|c|c|c|c|c|c|c|c|}
\hline \multirow{3}{*}{ Skor } & \multicolumn{8}{|c|}{ Lama Penyeduhan Minuman Kopi Seduh Dingin } \\
\hline & \multicolumn{2}{|c|}{$6 \mathrm{Jam}$} & \multicolumn{2}{|c|}{$12 \mathrm{Jam}$} & \multicolumn{2}{|c|}{$18 \mathrm{Jam}$} & \multicolumn{2}{|c|}{$24 \mathrm{Jam}$} \\
\hline & $\mathrm{N}$ & $\%$ & $\mathrm{n}$ & $\%$ & $\mathrm{n}$ & $\%$ & $\mathrm{n}$ & $\%$ \\
\hline 6.00 & 9 & $60 \%$ & & & 1 & $6.67 \%$ & & \\
\hline 6.25 & 4 & $26.67 \%$ & 1 & $6.67 \%$ & 1 & $6.67 \%$ & & \\
\hline 6.50 & 2 & $13.33 \%$ & 6 & $40 \%$ & 3 & $20 \%$ & 1 & $6.67 \%$ \\
\hline 6.75 & & & 5 & $33.33 \%$ & 1 & $6.67 \%$ & 2 & $13.33 \%$ \\
\hline 7.00 & & & 3 & $20 \%$ & 7 & $46.67 \%$ & 10 & $66.67 \%$ \\
\hline 7.25 & & & & & 2 & $13.33 \%$ & 2 & $13.33 \%$ \\
\hline \multicolumn{9}{|l|}{7.50} \\
\hline Jumlah (N) & 15 & $100 \%$ & 15 & $100 \%$ & 15 & $100 \%$ & 15 & $100 \%$ \\
\hline Mean & & & & & & & & 95 \\
\hline
\end{tabular}

Hasil penelitian pada aspek body kopi seduh dingin dengan lama waktu penyeduhan yang berbeda dieperoleh nilai rata-rata 6,17 untuk lama penyeduhan 6 jam, 6,67 untuk lama penyeduhan 12 jam, 6,80 untuk lama penyeduhan 18 jam dan 6,95 untuk lama penyeduhanb 24 jam. Pada uji kruskal wallis diperoleh nilai 26,42>9,4 dengan taraf signifikansi $\alpha=0,05$ yang berarti terdapat pengaruh lama penyeduhan kopi seduh dingin terhadap aspek body

\section{KESIMPULAN}

Hasil perhitungan uji kruskal wallis pada kopi seduh dingin dengan lama penyeduhan berbeda yakni $6,12,18$ dan 24 jam menunjukan terdapat perbedaan nyata atau terdapat pengaruh lama penyeduhan terhadap kopi seduh dingin. Berdasarkan data yang diterima kopi seduh dingin dengan lama penyeduhan 24 jam memiliki penilaian yang paling baik meskipun tidak terdapat perbedaan nilai yang terlalu jauh bila dibandingkan dengan kopi seduh dingin dengan lama penyeduhan 6,12 dan 18 jam. 


\section{REFERENSI}

Alat Uji. (2018). Cara Penggunaan dan Perawatan Refractometer. https://www.alatuji.com/index.php?/article/detail/638/cara-penggunaan-dan-perawatan-refractometer. Diakses 17 Juni 2020.

International Coffee Organization. (2020). World Coffee Consumption. http://www.ico.org/prices/new-consumption-table.pdf. Diakses 5 Juni 2020.

Rao, Scott. (2008). The Professional Barista's Handbook : an Expert Guide to Preparing Espresso, Coffee, and Tea. United States of America: Scoot Rao

Wachamo, Hailu Lire. (2017). Review on Health Benefit and Risk of Coffee Consumption. Ethiopian Institute of Agricultural Reesearch.

Wikipedia (2019) https://id.wikipedia.org/wiki/Uji_organoleptik. Diakses 28 September 2019

Zarwinda, Irma \& Dewi Sartika. (2018). Pengaruh Suhu dan Waktu Ekstraksi terhadap Kafein Dalam Kopi. Lantanida Journal. 